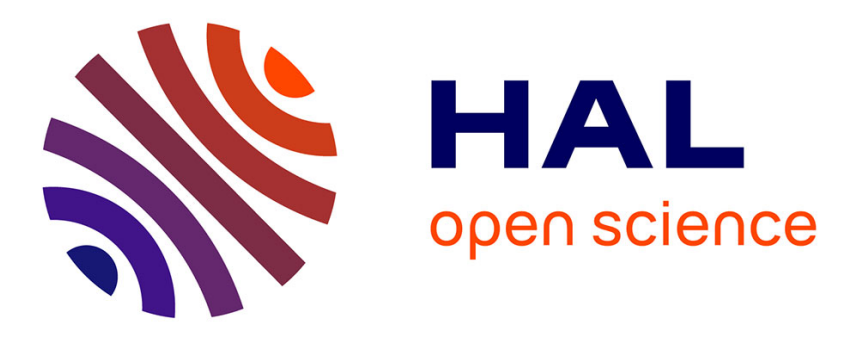

\title{
Contribution of health motives to cannabis use among college students
}

Henri Chabrol, Jean Chassagne, Jonathan Bronchain, Patrick Raynal, Kate B Carey

\section{- To cite this version:}

Henri Chabrol, Jean Chassagne, Jonathan Bronchain, Patrick Raynal, Kate B Carey. Contribution of health motives to cannabis use among college students. Addiction Research and Theory, 2020, 28 (3), pp.269-273. 10.1080/16066359.2019.1680648 . hal-03192996

\section{HAL Id: hal-03192996 https://hal.science/hal-03192996}

Submitted on 8 Apr 2021

HAL is a multi-disciplinary open access archive for the deposit and dissemination of scientific research documents, whether they are published or not. The documents may come from teaching and research institutions in France or abroad, or from public or private research centers.
L'archive ouverte pluridisciplinaire HAL, est destinée au dépôt et à la diffusion de documents scientifiques de niveau recherche, publiés ou non, émanant des établissements d'enseignement et de recherche français ou étrangers, des laboratoires publics ou privés. 


\title{
Contribution of Health Motives to Cannabis Use Among College Students
}

\author{
Henri Chabrol, Jean Chassagne, Jonathan Bronchain*, Patrick Raynal \\ Université de Toulouse, France \\ Kate B. Carey \\ Brown University, USA
}

Corresponding author :

J. Bronchain, UFR de Psychologie, Université de Toulouse-Jean Jaurès,

5 allées Antonio Machado, 31058 Toulouse cedex 9

phone number : 33781533109

fax number : 33561257093

e-mail address: jonathan.bronchain@etu.univ-tlse2.fr 


\title{
CANNABIS USE AND HEALTH MOTIVES
}

\begin{abstract}
The Marijuana Motives Measure (MMM) is commonly used to explore the role of motives in cannabis use and related problems. A recent study suggested that a new Health motives subscale (using cannabis to improve sleep, form, energy, appetite, health) was the strongest motive associated with problematic use among high-school students. The aim of our study was to examine the predictive value of Health motives for cannabis use among college students. Participants were 328 French college students who used cannabis at least once during the last six months and completed the Cannabis Use Disorder Identification TestRevised (CUDIT-R) assessing the severity of symptoms related to cannabis use disorder (CUD) and the Marijuana Motives Mesure (MMM). Twenty-two percent reached the cut-off score for likely moderate-severe DSM-5 CUD. Multiple regression analyses showed that Health motives were the strongest predictor for the severity of symptoms related to CUD relatively to all other motives. Enhancement and Expansion were also positively associated to symptoms of CUD, far more here than in previous studies among adolescents. This study replicates the findings of a previous study in high-school students. Health motives were found to be a strong predictor of CUD symptoms in college and high-school students which may have implication for both prevention and treatment of cannabis use problems.

Keywords: cannabis use; motives; health; college students.
\end{abstract}




\section{CANNABIS USE AND HEALTH MOTIVES}

\section{Introduction}

Marijuana is one of the most commonly used psychoactive substance among college students in Europe and the USA (e.g, Arria et al., 2017; Helmer et al., 2014). Although its legalization is becoming widespread, it is still illegal in France where our study was conducted. Cannabis use among college students is associated with adverse academic and health outcomes (e.g., Suerken et al., 2016). Understanding motives for cannabis use and their relation to dependence is critical to developing etiological models of cannabis use as well as the development of effective interventions for prevention and treatment (Benshop et al., 2015; Simons et al., 1998). Simons et al. developed the Marijuana Motives Measure (MMM) composed of five subscales (Enhancement of positive affects, Expansion of experiential awareness, Coping, Social conformity, and Social cohesion) which were significant predictors of marijuana use and use-related problems (Simons et al., 1998). Simons et al. (2005) later showed that Coping motives were motives most directly associated with cannabis use-related problems. In two studies using the MMM in young adults (van der Pol et al., 2013) and adolescents (Fox et al., 2011), only Coping was a significant predictor of dependence symptoms. Coping motives were also found to be significantly associated to cannabis userelated problems, even after accounting for the variance attributable to cannabis use frequency (Buckner, 2013). In their study, Banes et al. (2014) reported a significant decrease in frequency of motives used following treatment of CUD. Decreases in Expansion motives were associated with poorer treatment outcome while decreases in Coping motives were associated with better treatment outcome. In a more recent study by Villarosa-Hurlocker et al. (2019), Coping motives significantly mediated the relationship between social anxiety symptoms and substance use problems. Spradlin and Cuttler (2019) also observed that Coping motives were significant mediators on the relationship between stress and frequency of cannabis use and between stress and problematic cannabis use. 


\section{CANNABIS USE AND HEALTH MOTIVES}

In Lee et al. (2007), participants were asked to "think about what motivates you to use marijuana and briefly list the top five reasons in rank order". In their study, experimentation was consistently associated with less cannabis use and fewer related problems. Enjoyment, habit, activity enhancement, and altered perception were associated with more use and more related problems. In a recent meta-analysis, Bresin and Mekawi (2019) found significant positive correlations with marijuana use frequency for Coping, Enhancement, Social, and Expansion motives, but not for Conformity.

Since the MMM was developed, there have been attempts to identify additional motives for cannabis use. Lee et al. (2009) developed the Comprehensive Marijuana Motives Questionnaire (CMMQ), which consisted of 12 subscales. Few motives showed a unique association to cannabis use or related problems, beyond what was accounted for by the MMM: only Boredom, Relative Low Risk, and Sleep/Rest were uniquely and positively associated with cannabis use, while Altered Perception was uniquely and positively associated with meeting abuse and/or dependence criteria. Blevins et al. (2016) reported significant decreases in the frequency of motives used following treatment, similarly to Banes et al. (2014) with the MMM. Haug et al. (2017) found that the Coping subscale of the CMMQ was a significant predictor of problematic cannabis use. Benschop et al. (2015) used the MMM supplemented by a Routine motives subscale (composed of boredom and habit). Only Routine and Coping motives were uniquely associated to cannabis dependence. These studies yielded few new motives uniquely associated to cannabis use or related problems suggesting the value of further exploration of motives for using cannabis. Chabrol, et al. (2017) explored the role of six new subscales (Health, Autonomy, Defiance, Escape, Sensation and Sexuality) based on author (HC) 30 years of experience with adolescent cannabis users as a child and adolescent psychiatrist. Health motives (using cannabis to be on form, improve sleep, energy, appetite, health) were the only one to be significantly associated to both frequency of use and 


\section{CANNABIS USE AND HEALTH MOTIVES}

problematic use symptoms. Multiple regression analyses controlling for psychopathological variables showed that the Health motives and the Coping motives were the only significant predictors of cannabis use frequency and that Health motives were the only motives uniquely and positively related to problematic use symptoms. The aim of the present study was to explore the contribution of Health motives to cannabis use and severity of symptoms related to cannabis use disorder (CUD) among college students after controlling for the main others motives of use.

\section{Methods}

\section{Participants and Procedure}

The data were collected through an online survey, administrated in French, that was distributed to French-speaking students. The link was shared on social networks in groups specifically dedicated to students. Informed consent was obtained from all participants and they were informed that answers to the questionnaires would remain anonymous. The objectives of the study were presented to all participants at the beginning of the online questionnaire, specifying that this was a study on personality and behaviors. No compensation was offered to participate in the study. The participants were provided with the possibility to contact one of the authors (PR) via email for further information or to receive referral. All participants had to confirm their student status. The final sample consisted of 328 French students, 250 females $(76.2 \%)$ and 78 males $(23.8 \%)$ (mean age of females $=19.9 \pm 1.7$; mean age of males $=21.3 \pm 2.3$; age range $=18-30)$ who used cannabis at least once during the last six months. Forty-four point five percent of them were in first year of college, $25.6 \%$ in second year, $18.6 \%$ in third year. Seven percent were in first year of master degree, $2.1 \%$ in second year and $2.1 \%$ were doctoral students. As regards the participants' fields of study, $52.7 \%$ were studying social sciences, $10.4 \%$ literature, $7.4 \%$ law, $6.7 \%$ science or engineering, $4.6 \%$ medicine or paramedical studies, $3 \%$ art or design, $2.4 \%$ history, 


\section{CANNABIS USE AND HEALTH MOTIVES}

geography or political science, $1.8 \%$ art history or archaeology, $1.5 \%$ economics, commerce, management or communication, $1.5 \%$ education or pedagogy, $1 \%$ sports, and $4.3 \%$ were studying other subjects. The study followed the guidelines of the Helsinki declaration and ethical issues of the current research were explored at a research meeting.

\section{Measures}

The frequency of cannabis use and the severity of symptoms related to CUD were assessed with the CUD Identification Test-Revised (CUDIT-R; Adamson et al., 2010) which is an 8-item self- report screening tool that is sensitive and specific for DSM-5 CUD. The participants had to report frequency of use and how often they had been involved in the 7 described behaviors during the last six months exploring likelihood of CUD (e.g., item 1: "How often do you use cannabis?"; item 4: "How often during the past 6 months did you fail to do what was normally expected from you because of using cannabis?"). Responses range from 0 (never) to 4 (4 times or more per week). Total scores vary from 0 to 32 . Higher scores indicate greater likelihood of CUD. In community samples, CUDIT-R total score of 13 or more is a suggested cut-off for identifying possible moderate-severe cases of DSM-5 CUD (Adamson et al., 2010; Bruno et al., 2013). The first item measuring frequency of use was used as an inclusion criteria to differentiate cannabis users $(>0)$ and non-users $(=0)$ and as a continuous indicator of the frequency of use.

Motives for cannabis use were assessed with the Marijuana Motives Measure (MMM; Simons et al., 1998). It contains 25 items rated on a 5-point scale ranging from 1 (almost never/never) to 5 (almost always/always). The MMM is composed of five subscales: Coping (e.g., "I use marijuana to forget my worries"), Enhancement (e.g., "I use marijuana to get high"), Social (e.g., "I use marijuana to be sociable"), Conformity (e.g., "I use marijuana so I won't feel left out"), Expansion (e.g., "I use marijuana to expand my awareness"). Health motives were measured through 5 items assessing cannabis use to improve sleep, general 


\section{CANNABIS USE AND HEALTH MOTIVES}

form, energy, appetite, and health ("I use cannabis to sleep better"; "I use cannabis to be on form"; "I use cannabis to feel more energetic"; "I use cannabis to have a better appetite"; "I use cannabis to feel healthier").

\section{Results}

\section{Descriptive Statistics}

Among our initial 1034 students population, cannabis use was reported at equal rates by females $(253 ; 31 \%)$ and males $(77 ; 36 \%)(\mathrm{p}=.16) .22 \%(\mathrm{n}=72)$ reached the CUDIT-R cut-off score of 13 for possible moderate-severe cases of DSM-5 CUD, including 19\% ( $\mathrm{n}=$ $49)$ of females and $30 \%(n=23)$ of males $(p=.04)$. Females reported a lower frequency of use than males: average use for females was slightly lower than 2-4 times whereas average use for males was slightly higher than 2-4 times a month. Female users had lower scores on the CUDIT-R than males. All descriptive statistics are shown in Table 1.

\section{Correlations Between Variables}

Frequency of use and CUDIT-R scores (excluding the frequency item) were highly correlated $(r=.74)$. Motives were moderately inter-correlated ( $r$ range $=30-.53)$. All motives (except for Conformity) were weakly to moderately correlated to cannabis use frequency and symptoms of CUD. Only Health motives were strongly correlated to these two variables. (Table 2).

\section{Multiple Regression Analyses Predicting frequency of cannabis use and severity of symptoms related to CUD}

Multiple regression analyses were conducted to identify unique associations between motives and frequency of cannabis use and between motives and severity of symptoms of CUD. Gender and motives were considered simultaneously in the same regression equation. The participants-to-predictors ratio was adequate for multiple regression analysis as the simplest rule of thumb is $N \geq 104+m$ (where $m$ is the number of predictors) for testing 


\section{CANNABIS USE AND HEALTH MOTIVES}

individual predictors (Tabachnick \& Fidell, 2001). A square root transformation was used on the CUDIT-R scores, and Coping, Social, Expansion, Conformity and Health motives to reduce skewness. All predictor variables had tolerance values $>0.4$ excluding multicollinearity.

As shown in Table 3, the multiple $R^{2}$ was .30 , indicating that the seven variables explained $30 \%$ of the variance in the frequency of cannabis use, $F(7,320)=19.22, p<.001$. The unique contribution of each predictor was reported with standardized regression coefficient $(\beta), t$ and $p$-value. In the full model, gender was not a significant predictor. All motives were positively and significantly associated with the frequency of cannabis use with the exception of the Social motives which were negatively and significantly associated, and the Conformity motives which were not significant predictor. Health motives were the strongest predictor of the frequency of cannabis use.

As shown in Table 4 , the multiple $R^{2}$ was .31 , indicating that the seven variables explained $31 \%$ of the variance in the severity of symptoms of CUD, $F(7,320)=20.51, p<$ .001. In the full model, gender was a significant but weak predictor. All motives were positively and significantly associated with the severity of symptoms of CUD with the exception of the Social motives which was negatively and significantly associated, and the Enhancement and Conformity motives who were not significant predictors. Health motives were the strongest predictor of the severity of symptoms of CUD.

\section{Discussion}

Among cannabis users, $19 \%$ of females and $30 \%$ of males scored for possible cases of DSM-5 CUD, in keeping with previous studies in French college students (Raynal \& Chabrol, 2016). Regression analysis showed that all motives (with the exception of the Conformity motives) were significantly associated with the frequency of cannabis use. Severity of symptoms related to CUD was only significantly associated with Coping, Expansion and Health motives. 


\section{CANNABIS USE AND HEALTH MOTIVES}

Coping and Expansion motives were positively associated to symptoms of CUD and to frequency of cannabis use, paralleling the studies by Simons et al. (1998) and Lee et al. (2009). In our study, Social motives were negatively associated with the frequency of cannabis use. It's possible that this negative association was due to the fact that Social motives may be associated with less frequent cannabis use, limited to social occasions. Enhancement motives were only positively associated with the frequency of cannabis use.

Health motives (using cannabis to improve sleep, form, energy, appetite, health) were the strongest predictor of frequency of cannabis use and severity of symptoms related to CUD in the present study, such as in our previous study conducted among high-school students. The relevance of Health motives among adolescents and young adults may reflect the high proportion of French high-school and college students reporting feeling in bad health, having sleep problems, and using self-medication (e.g., Observatoire National de la Vie Etudiante, 2017). The importance of Health motives is partially consistent with Lee et al.'s study, which found that Coping and Sleep/Rest motives were associated with more cannabis-related problems, as our Health motive shares sleep with the Sleep/rest subscale. However, the crosssectional design of the study precludes inferences about causal relationships. The association of Health motives to use frequency and symptoms related to CUD may be bidirectional, and several hypotheses can be offered for how they might be related. For example, Health motives, such as using cannabis to improve sleep, may facilitate daily use and dependence. On the other hand, symptoms of dependence and withdrawal may increase the need to use to control for withdrawal symptoms such as poor sleep, decreased appetite, and tiredness. Health motives may also reflect the need to alleviate withdrawal symptoms which may begin between 1-3 days after last use, peak at 2-6 days and last 4-14 days according to Budney et al. (2003). Another possibility is that those who use more cannabis justify their drug use to themselves or others by believing and saying that cannabis is good for one's health. This 


\section{CANNABIS USE AND HEALTH MOTIVES}

belief may be facilitated by the media exposure to the possible health benefits of medical cannabis, as drug users tend to focus on the information that supports their consumption. Moreover, the liberalization of cannabis policy, such as legalization of recreational cannabis, by several jurisdictions may have contributed to lower perception of harms and higher perception of health benefits (e.g., Sarvet et al., 2018). Since change in motives may partially mediate the effects of treatment, targeting specific cannabis use motives in interventions may significantly improve CUD treatment outcomes reported by Banes et al. (2014) and Blewins et al. (2016). That leads us to wonder if targeting Health motives could also decrease frequency of use and negative consequences of use following an intervention. Further studies will have to study the outcome of targeting this variable in order to improve future interventions.

This study has several limitations. Although internet data collection methods, using online completion of self-report questionnaires have shown to be consistent with more traditional methods (Gosling et al., 2004), the possibility that participant self-selection may have biased the results cannot be excluded. However, there is also scientific evidence available that Internet-based data collections are commonly able to produce generalizable results (e.g., Best et al., 2001). Thus, the high proportion of women in our sample reflects the gender-ratio in French universities, which were attended by $57 \%$ of women in general, and up to $70 \%$ in social sciences (Ministère de l'Enseignement supérieur, de la Recherche et de l'Innovation, 2018). Moreover, the cross-sectional design prevents from inferring causal relationships. Longitudinal studies are needed to clarify the causal relationships between Health motives and symptoms of CUD. However, even if the relationships between Health motives and cannabis problematic use are bidirectional, Health motives may contribute to increased use and dependence, and taking into account Health motives in both prevention and 


\section{CANNABIS USE AND HEALTH MOTIVES}

treatment may be critical. Careless responding or social desirability scale could be added in future study to reduce some of the respondents' biases and get more accurate results.

\section{Conclusion}

The present study showed that having higher motivations to use cannabis to improve subjective health is associated with higher levels of symptoms of CUD. This study suggests the relevance of assessing the Health motives for cannabis use to help identify those at greatest risk for developing frequent use and dependence symptoms. It also suggests the interest of intervention directly addressing Health motives, for both prevention and treatment of cannabis use problems among young adults.

\section{Declaration of interest}

The authors report no conflicts of interest. The authors alone are responsible for the content and writing of the paper.

\section{Funding}

This study received no funding. 


\section{CANNABIS USE AND HEALTH MOTIVES}

\section{References}

Adamson, S. J., Kay-Lambkin, F. J., Baker, A. L., Lewin, T. J., Thornton, L., Kelly, B. J., \& Sellman, J. D. (2010). An improved brief measure of cannabis misuse: the CUDs Identification Test-Revised (CUDIT-R). Drug and Alcohol Dependence, 110, 137143. doi: 10.1016/j.drugalcdep.2010.02.017

Arria, A. M., Caldeira, K. M., Allen, H. K., Bugbee, B. A., Vincent, K. B., \& O’Grady, K. E. (2017). Prevalence and incidence of drug use among college students: an 8-year longitudinal analysis. The American Journal of Drug and Alcohol Abuse, 43, 711-718. doi :10.1080/00952990.2017.1310219

Banes, K. E., Stephens, R. S., Blevins, C. E., Walker, D. D., \& Roffman, R. A. (2014). Changing motives for use: Outcomes from a cognitive-behavioral intervention for marijuana-dependent adults. Drug and alcohol dependence, 139, 41-46. doi: 10.1016/j.drugalcdep.2014.02.706

Benschop, A., Liebregts, N., van der Pol, P., Schaap, R., Buisman, R., van Laar, M., Korf, D. J. (2015). Reliability and validity of the Marijuana Motives Measure among young adult frequent cannabis users and associations with cannabis dependence. Addictive Behaviors, 40, 91-95. doi:10.1016/j.addbeh.2014.09.003

Best, S. J., Krueger, B., Hubbard, C., \& Smith, A. (2001). An assessment of the generalizability of internet surveys. Social Science Computer Review, 19, 131-145. doi: $10.1177 / 089443930101900201$

Blevins, C. E., Banes, K. E., Stephens, R. S., Walker, D. D., \& Roffman, R. A. (2016). Change in motives among frequent cannabis-using adolescents: Predicting treatment outcomes. Drug and alcohol dependence, 167, 175-181.

doi: 10.1016/j.drugalcdep.2016.08.018

Bresin, K., \& Mekawi, Y. (2019). Do marijuana use motives matter? Meta-analytic 


\section{CANNABIS USE AND HEALTH MOTIVES}

associations with marijuana use frequency and problems. Addictive Behaviors, 106102. doi: 10.1016/j.addbeh.2019.106102

Bruno, R., Marshall, S., \& Adamson, S. (2013). Screening for DSM-5 cannabis dependence using the Cannabis Use Identification Test-Revised (CUDIT-R). Poster presented at the Australasian Professional Society on Alcohol and other Drugs.

Budney, A. J., Moore, B. A., Vandrey, R. G., \& Hughes, J. R. (2003). The time course and significance of cannabis withdrawal. Journal of abnormal psychology, 112(3), 393. doi: 10.1037/0021-843x.112.3.393

Buckner, J. D. (2013). College cannabis use: The unique roles of social norms, motives, and expectancies. Journal of studies on alcohol and drugs, 74(5), 720-726. doi: $10.15288 /$ jsad.2013.74.720

Chabrol, H., Beck, C., \& Laconi, S. (2017). Contribution of health motive to cannabis use among high-school students. Addictive Behaviors, 64, 54-56. doi:10.1016/j.addbeh.2016.08.011

Clark, L.A., \& Watson, D. (1995). Constructing validity: basic issues in objective scale development. Psychological Assessment, 7, 309-319.

Cohen, P., Chen, H., Crawford, T. N., Brook, J. S., \& Gordon, K. (2007). Personality disorders in early adolescence and the development of later substance use in the general population. Drug and Alcohol Dependence, $88 S$, S71-S84. doi:10.1016\%2Fj.drugalcdep.2006.12.012

Fox, C. L., Towe, S. L., Stephens, R. S., Walker, D. D., \& Roffman, R. A. (2011). Motives for cannabis use in high-risk adolescent users. Psychology of Addictive Behaviors, 25, 492-500. doi:10.1037/a0024331 


\section{CANNABIS USE AND HEALTH MOTIVES}

Gardner, Kathryn \& Qualter, Pamela. (2009). Reliability and validity of three screening measures of borderline personality disorder. Personality and Individual Differences. 46. 636-641. 10.1016/j.paid.2009.01.005.

Gosling, S. D., Vazire, S., Srivastava, S., \& John, O. P. (2004). Should we trust Web-based studies? A comparative analysis of six preconceptions about Internet questionnaires. American Psychologist, 59, 93-104. doi:10.1037/0003-066X.59.2.93

Haug, N. A., Padula, C. B., Sottile, J. E., Vandrey, R., Heinz, A. J., \& Bonn-Miller, M. O. (2017). Cannabis use patterns and motives: a comparison of younger, middle-aged, and older medical cannabis dispensary patients. Addictive Behaviors, 72, 14-20. doi:10.1016/j.addbeh.2017.03.006

Helmer, S. M., Mikolajczyk, R. T., McAlaney, J., Vriesacker, B., Van Hal, G., Akvardar, Y., ... \& Bewick, B. M. (2014). Illicit substance use among university students from seven European countries: A comparison of personal and perceived peer use and attitudes towards illicit substance use. Preventive Medicine, 67, 204-209. doi:10.1016/j.ypmed.2014.07.039

Hyler, S. E. (1994). Personality Questionnaire (PDQ-4+). New York: New York State Psychiatric Institute.

Lee, C. M., Neighbors, C., \& Woods, B. A. (2007). Marijuana motives: Young adults' reasons for using marijuana. Addictive behaviors, 32(7), 1384-1394. doi: 10.1016/j.addbeh.2006.09.010

Lee, C. M., Neighbors, C., Hendershot, C. S., \& Grossbard, J. R. (2009). Development and preliminary validation of a comprehensive marijuana motives questionnaire. Journal of Studies on Alcohol and Drugs, 70, 279-287. doi:10.15288/jsad.2009.70.279

Ministère de l'Enseignement supérieur, de la Recherche et de l'Innovation. (2018). Les étudiants inscrits dans les universités françaises en 2017-2018. Systèmes d'Information 


\section{CANNABIS USE AND HEALTH MOTIVES}

et des Études Statistiques. Retrieved from http://cache.media.enseignementsuprecherche.gouv.fr/file/2018/44/3/NI_2018-07_Effectifs_universitaires_1011443.pdf

Observatoire national de la vie étudiante. (2017). La santé des étudiants - Enquête nationale conditions de vie des étudiant-e-s 2016 [Students'health : Student Living Conditions survey by the National Observatory of Student Life 2016]. [Monograph]. Retrieved from https://www.ove-national.education.fr

Raynal, P., \& Chabrol, H. (2016). Association between schizotypal and borderline personality disorder traits, and cannabis use in young adults. Addictive Behaviors, 60, 144-147. doi:10.1016/j.addbeh.2016.04.018

Sarvet, A. L., Wall, M. M., Keyes, K. M., Cerdá, M., Schulenberg, J. E., O’Malley, P. M., ... \& Hasin, D. S. (2018). Recent rapid decrease in adolescents' perception that marijuana is harmful, but no concurrent increase in use. Drug and Alcohol Dependence, 186, 6874. doi:10.1016/j.drugalcdep.2017.12.041

Simons, J., Correia, C. J., Carey, K. B., \& Borsari, B. E. (1998). Validating a five-factor Marijuana Motives Measure: Relations with use, problems, and alcohol motives. Journal of Counseling Psychology, 45, 265-273. doi:10.1037/0022-0167.45.3.265

Simons, J. S., Gaher, R. M., Correia, C. J., Hansen, C. L., \& Christopher, M. S. (2005). An affective-motivational model of marijuana and alcohol problems among college students. Psychology of Addictive Behaviors, 19(3), 326. doi: 10.1037/0893-164X.19.3.326

Suerken, C. K., Reboussin, B. A., Egan, K. L., Sutfin, E. L., Wagoner, K. G., Spangler, J., \& Wolfson, M. (2016). Marijuana use trajectories and academic outcomes among college students. Drug \& Alcohol Dependence, 162, 137-145. doi:10.1016/J.Drugalcdep.2016.02.041 


\section{CANNABIS USE AND HEALTH MOTIVES}

Tabachnick, B. G., \& Fidell, L. S. (2001). Using multivariate statistics (4th ed). Boston : Allyn and Bacon.

van der Pol, P., Liebregts, N., de Graaf, R., Korf, D. J., van den Brink, W., \& van Laar, M. (2013). Predicting the transition from frequent cannabis use to cannabis dependence: A three-year prospective study. Drug and Alcohol Dependence, 133, 352-359. doi:10.1016/j.drugalcdep.2013.06.009

Villarosa-Hurlocker, M. C., Bravo, A. J., Pearson, M. R., Protective Strategies Study Team, Prince, M. A., Madson, M. B., ... \& Cuttler, C. (2019). The relationship between social anxiety and alcohol and marijuana use outcomes among concurrent users: a motivational model of substance use. Alcoholism: clinical and experimental research, 43(4), 732-740. doi: 10.1111/acer.13966 
Table 1 - Descriptive Statistics

\begin{tabular}{|c|c|c|c|c|c|c|c|}
\hline & \multirow[b]{2}{*}{$\alpha$} & \multirow[b]{2}{*}{ Skewness } & \multirow[b]{2}{*}{ Kurtosis } & \multicolumn{2}{|c|}{ Male $(n=78)$} & \multicolumn{2}{|c|}{ Female $(n=250)$} \\
\hline & & & & $M$ & $S D$ & $M$ & $S D$ \\
\hline Cannabis Use Frequency & & .13 & -.94 & 1.83 & .94 & 1.56 & .90 \\
\hline Symptoms of CUD & .80 & .91 & .19 & 8.54 & 6.31 & 6.61 & 5.26 \\
\hline \multicolumn{8}{|l|}{ Motives } \\
\hline Coping & .88 & 1.07 & .25 & 8.27 & 4.77 & 7.89 & 3.93 \\
\hline Enhancement & .82 & -.18 & -.73 & 15.87 & 4.82 & 15.08 & 5.24 \\
\hline Social & .78 & .81 & .27 & 13.00 & 5.18 & 12.82 & 5.05 \\
\hline Conformity & .64 & 2.29 & 6.39 & 6.32 & 2.14 & 5.94 & 1.54 \\
\hline Expansion & .84 & 1.26 & .64 & 10.14 & 5.51 & 8.79 & 4.39 \\
\hline Health & .70 & 2.17 & 6.61 & 7.90 & 3.44 & 7.40 & 3.05 \\
\hline
\end{tabular}

Total Sample: $N=328$

Note $: \mathrm{CUD}=$ Cannabis Use Disorder; $\mathrm{SD}=$ Standard Deviation. 
Table 2 - Correlations between Cannabis Use Frequency, Severity of Symptoms related to CUD and each motives among Cannabis Users $(N=328)$.

\begin{tabular}{|c|c|c|c|c|c|c|c|}
\hline & CUF & CUD & 1 & 2 & 3 & 4 & 5 \\
\hline Cannabis Use Frequency & &, $78^{* *}$ & & & & & \\
\hline \multicolumn{8}{|l|}{ Motives } \\
\hline 1-Coping & $.36^{* *}$ & $.42 * *$ & & & & & \\
\hline 2-Enhancement & $.31 * *$ & $.25^{* *}$ & $.30 * *$ & & & & \\
\hline 3-Social & $.15 * *$ & $.16^{* *}$ & $.31 * *$ & $.54 * *$ & & & \\
\hline 4-Conformity & .01 & .02 & .02 & .07 & $.34 * *$ & & \\
\hline 5-Expansion & $.37 * *$ & $.41 * *$ & $.40 * *$ & $.36^{* *}$ & $.43 * *$ & $.13 *$ & \\
\hline 6-Health & $.46^{* *}$ & $.51 * *$ & $.54 * *$ & $.33 * *$ & $.38 * *$ & $.15^{* *}$ & $.53 * *$ \\
\hline
\end{tabular}

Note $: * p<.05 * * p<.01$

$\mathrm{CUF}=$ Cannabis Use Frequency; CUD $=$ Cannabis Use Disorder 
Table 3 - Multiple Regression Analyses predicting Frequency of

Cannabis Use among Cannabis Users $(\mathbf{N}=328)$

\begin{tabular}{llccc} 
& & $\beta$ & $t$ & $p$ \\
\hline Gender & & -.08 & -1.59 & .11 \\
Motives & & & \\
& Coping & .12 & 2.05 & .04 \\
& Enhancement & .21 & 3.58 & $<.001$ \\
& Social & -.17 & -2.65 & $<.01$ \\
& Conformity & -.05 & -.90 & .37 \\
& Expansion & .15 & 2.62 & $<.01$ \\
& Health & .32 & 5.12 & $<.001$ \\
\hline$R^{2}$ & & $.30 * *$ & & \\
\hline
\end{tabular}

Note: $* * p<.01$ 
Table 4 - Multiple Regression Analyses predicting Severity of

Symptoms related to CUD among Cannabis Users $(N=328)$

\begin{tabular}{llccc} 
& & $\beta$ & $t$ & $p$ \\
\hline Gender & & -.10 & -2.00 & .05 \\
Motives & & & \\
& Coping & .20 & 3.58 & $<.001$ \\
& Enhancement & .05 & .84 & .40 \\
& Social & -.09 & -.15 & .13 \\
& Conformity & -.02 & .40 & .69 \\
& Expansion & .17 & 2.84 & $<.01$ \\
& Health & .31 & 5.07 & $<.001$ \\
\hline$R^{2}$ & & $.31 * *$ & & \\
\hline
\end{tabular}

Note: $* * p<.01$ 